\title{
Expression of the bipolar see-saw in Antarctic climate records during the last deglaciation
}

\author{
B. Stenni ${ }^{1}$, D. Buiron ${ }^{2}$, M. Frezzotti ${ }^{3 \star}$, S. Albani ${ }^{4}$, C. Barbante ${ }^{5}$, E. Bard ${ }^{6}$, J. M. Barnola ${ }^{2 \dagger}$, M. Baroni ${ }^{6}$, \\ M. Baumgartner ${ }^{7}$, M. Bonazza', E. Capron ${ }^{8}$, E. Castellano ${ }^{9}$, J. Chappellaz ${ }^{2}$, B. Delmonte ${ }^{4}$, S. Falourd ${ }^{8}$, \\ L. Genoni ${ }^{1}$, P. lacumin ${ }^{10}$, J. Jouzel ${ }^{8}$, S. Kipfstuhl ${ }^{11}$, A. Landais ${ }^{8}$, B. Lemieux-Dudon' ${ }^{2}$, V. Maggi ${ }^{4}$, \\ V. Masson-Delmotte ${ }^{8}$, C. Mazzola ${ }^{4}$, B. Minster ${ }^{8}$, M. Montagnat ${ }^{2}$, R. Mulvaney ${ }^{12}$, B. Narcisi ${ }^{3}$, \\ H. Oerter ${ }^{11}$, F. Parrenin ${ }^{2}$, J. R. Petit ${ }^{2}$, C. Ritz ${ }^{2}$, C. Scarchilli ${ }^{3}$, A. Schilt ${ }^{7}$, S. Schüpbach ${ }^{7}$, J. Schwander ${ }^{7}$, \\ E. Selmo ${ }^{10}$, M. Severi ${ }^{9}$, T. F. Stocker ${ }^{7}$ and R. Udisti ${ }^{9}$
}

Ice-core records of climate from Greenland and Antarctica show asynchronous temperature variations on millennial timescales during the last glacial period'. The warming during the transition from glacial to interglacial conditions was markedly different between the hemispheres, a pattern attributed to the thermal bipolar see-saw ${ }^{2}$. However, a record from the Ross Sea sector of East Antarctica has been suggested to be synchronous with Northern Hemisphere climate change ${ }^{3}$. Here we present a temperature record from the Talos Dome ice core, also located in the Ross Sea sector. We compare our record with ice-core analyses from Greenland, based on methane synchronization ${ }^{4}$, and find clearly asynchronous temperature changes during the deglaciation. We also find distinct differences in Antarctic records, pointing to differences in the climate evolution of the Indo-Pacific and Atlantic sectors of Antarctica. In the Atlantic sector, we find that the rate of warming slowed between 16,000 and 14,500 years ago, parallel with the deceleration of the rise in atmospheric carbon dioxide concentrations and with a slight cooling over Greenland. In addition, our chronology supports the hypothesis that the cooling of the Antarctic Cold Reversal is synchronous with the Bølling-Allerød warming in the northern hemisphere 14,700 years ago 5 .

The period from about 8 to $25 \mathrm{kyr}$ before present (вР) includes the climate transition from the last glacial to the Holocene. As documented from polar ice cores and other climate archives, the pattern of climate changes throughout this transition is different between Antarctica and the surrounding Southern Ocean and the Northern Hemisphere. The steady Antarctic deglacial warming reaches a first maximum (Antarctic Isotopic Maximum AIM1; ref. 1) followed by an interruption towards cooler conditions during the Antarctic Cold Reversal (ACR). Conversely, Greenland records show two rapid-warming phases at the onset of the DansgaardOeschger-1 (DO1) event (Bølling-Allerød interstadial, B/A) and the
Holocene, separated by the Younger Dryas (YD) cold event ${ }^{5,6}$. This different sequence of events in the two hemispheres was related to the thermal bipolar see-saw ${ }^{1,2}$.

A prerequisite for studying the sequence and possible links between climate events in Greenland and Antarctica is the determination of their relative timing with sufficient accuracy ${ }^{7}$. For sites located on the East Antarctic Plateau (EAP), highresolution $\mathrm{CH}_{4}$ records ${ }^{4}$ have been used to place the European Project for Ice Coring in Antarctica (EPICA) Dronning Maud Land (EDML), and by extension the EPICA-Dome C (EDC) and Vostok, Antarctic ice cores ${ }^{8}$, on the layer-counted Greenland Ice Core Chronology 2005 (GICC05; see Supplementary Information). Although ice cores from the EAP show a coherent picture ${ }^{1,9,10}$, coastal ice cores are expected to be influenced by regional signals related to the surrounding ocean. So far, few ice cores from peripheral sites ${ }^{3,11}$ cover the last deglaciation. Critical for these coastal sequences is the relative depth of the last deglaciation with respect to bedrock, where ice thinning and deformation can perturb the stratigraphy. Furthermore, the extremely high variability of strong wind scouring can induce accumulation hiatuses.

The end of AIM1 as deduced from EAP ice cores is in phase with the first rapid temperature change in Greenland ${ }^{5}$ ( 14.7 kyr вP). This synchronicity supports the thermal bipolar see-saw conceptual model ${ }^{2}$, but is in apparent contradiction with the timing of climate change shown by the Taylor Dome (TYD) ice core in the Ross Sea sector $^{3}$. The timing of the stable isotope record from this coastal ice core seemed more similar to Greenland rather to Antarctic cores, with a first warming ending abruptly at $\sim 14 \mathrm{kyr}$ в $($ ref. 3 ), although this dating was already questioned ${ }^{12}$. Another coastal ice core, Law Dome (LD, East Antarctica), conversely, ends the first warming at $\sim 15 \mathrm{kyr}$ в , suggesting that the ACR does not follow the abrupt warming of DO1 (ref. 11). However, in this critical time interval, questions regarding the integrity of the timescale (TYD) and abrupt

\footnotetext{
${ }^{1}$ Department of Geosciences, University of Trieste, 34127 Trieste, Italy, ${ }^{2}$ Laboratoire de Glaciologie et de Géophysique de I'Environnement (CNRS-Université Joseph Fourier - Grenoble), 38402 Saint Martin d'Hères cedex, France, ${ }^{3}$ ENEA, CR Casaccia, 00123, Roma, Italy, ${ }^{4}$ Environmental Sciences Department, University of Milano Bicocca, 20126 Milano, Italy, ${ }^{5}$ Department of Environmental Sciences, University Cà Foscari of Venice, and IDPA-CNR, 30123 Venezia, Italy, ${ }^{6}$ CEREGE, UMR 6635 CNRS, IRD, University Aix-Marseille, Collège de France, Europôle de I'Arbois, BP80, 13545 Aix-en-Provence cédex 4, France, ${ }^{7}$ Climate and Environmental Physics, Physics Institute, University of Bern, 3012 Bern, Switzerland, ${ }^{8}$ Laboratoire des Sciences du Climat et de I'Environnement (IPSL/CEA-CNRS-UVSQ UMR 8212), CEA Saclay, 91191 Gif-sur-Yvette cédex, France, ${ }^{9}$ Department of Chemistry, University of Firenze, 50019 Sesto Fiorentino, Italy, ${ }^{10}$ Department of Earth Sciences, University of Parma, 43100 Parma, Italy,

${ }^{11}$ Alfred-Wegener-Institute for Polar and Marine Research, 27568 Bremerhaven, Germany, ${ }^{12}$ British Antarctic Survey, NERC, Cambridge, CB3 OET, UK.

†Deceased. *e-mail: massimo.frezzotti@enea.it.
} 


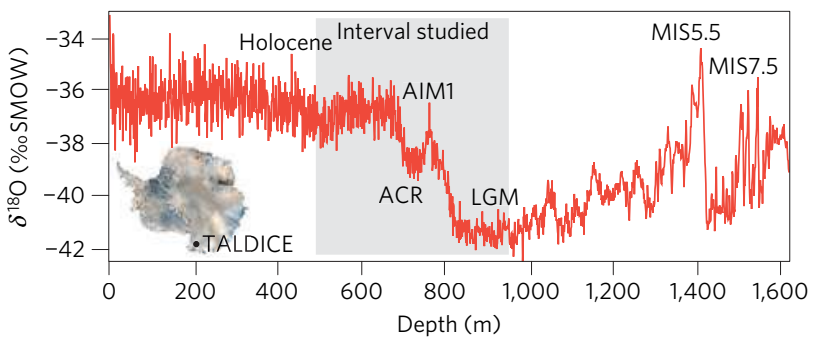

Figure 1 | The TALDICE stable isotope profile $\left(\delta^{18} 0\right)$ versus depth. The interval studied (8-25 kyr BP) is marked with grey shading. MIS 5.5, 7.5, LGM, AIM1 and ACR are indicated. The satellite image of Antarctica shows the location of the TALDICE ice core.

reduction in accumulation and thus limited time resolution (LD) render some earlier conclusions questionable.

Here we investigate a new 1,620-m-deep ice core drilled at Talos Dome (TLD) in the framework of the Talos Dome Ice Core (TALDICE) project (www.taldice.org). TLD is a peripheral dome of East Antarctica, located in the Ross Sea sector (Fig. 1). The moisture sources for TLD are mainly located in the Pacific and Indian sectors of the Southern Ocean (see Supplementary Information). The whole TALDICE ice core provides a palaeoclimate record covering the past $250 \mathrm{kyr}$ back to Marine Isotope Stage (MIS) 7.5 (Fig. 1). The TALDICE oxygen-isotope $\left(\delta^{18} \mathrm{O}\right.$, a proxy of local temperature $)$ record is presented here for the entire core (Fig. 1) and for the time window between 8 and $25 \mathrm{kyr}$ в (Fig. 2). TALDICE enables decadal-scale resolution during the last deglaciation owing to its relatively high accumulation rate $\left(80 \mathrm{~kg} \mathrm{~m}^{-2} \mathrm{yr}^{-1}\right)$. In this work, the TALDICE-1 chronology (see Supplementary Information) has been set up using a new inverse method $^{8}$, generating an optimal compromise between an a priori scenario set up from a glaciological model and chronological information from different time markers. $\mathrm{CH}_{4}$ data are used to synchronize ${ }^{4}$ TALDICE to the North Greenland Ice Core Project (NGRIP) ice core on the GICC05 age scale (see Supplementary Information), providing a relative synchronization error less than $100 \mathrm{yr}$ for the sharp $\mathrm{CH}_{4}$ transitions. TALDICE is the first coastal site with glaciological characteristics enabling accurate dating during the entire last deglaciation, which starts at around $800 \mathrm{~m}$ depth $(\sim 50 \%$ of the total ice thickness; see Supplementary Information). The resulting chronological uncertainty is $\pm 300 \mathrm{yr}$ between 8 and $15 \mathrm{kyr}, \pm 500 \mathrm{yr}$ back to $17.5 \mathrm{kyr}$ and up to $\pm 1.5 \mathrm{kyr}$ during the glacial period.

The pattern of $\delta^{18} \mathrm{O}$ during deglaciation is similar at TALDICE and EDC (Fig. 2), despite their different geographical positions and moisture sources (see Supplementary Information). The transition starts synchronously at $18.2 \pm 0.7 \mathrm{kyr}$ вр in TALDICE, EDML, EDC and Dome Fuji (DF) records (Figs 2 and 3), a few kiloyears before the Antarctic ice-sheet margin retreat ${ }^{13}$. Warming appears coeval with the ages reported for mid-latitude glacier retreat from both hemispheres ${ }^{14}$ and the rapid sea-level rise at $19 \mathrm{kyr}$ вр (ref. 13). The first part of deglaciation culminates in the AIM1 event at $14.7 \pm 0.3 \mathrm{kyr} \mathrm{вр}$, followed by the ACR cooling (Fig. 2) until $12.7 \pm 0.3 \mathrm{kyr} \mathrm{вP}$, and by the final warming towards the onset of Holocene. The ACR cooling appears with weaker $\delta^{18} \mathrm{O}$ amplitude in TALDICE than in EDC.

TALDICE confirms that the TYD chronology ${ }^{3}$ is almost certainly incorrect ${ }^{12}$ and enables us to refute that the deglacial history in the Ross Sea area was synchronous with the Northern Hemisphere (Figs 2 and 3).

During the Last Glacial Maximum (LGM) and the deglaciation, the comparison of $\delta^{18} \mathrm{O}$ records around Antarctica highlights regional features. Earlier studies revealed a smoother shape of glacial AIM events at EDML compared with EDC (ref. 15) as well as an identification of AIM2 at EDML-DF (refs 1,9) but not

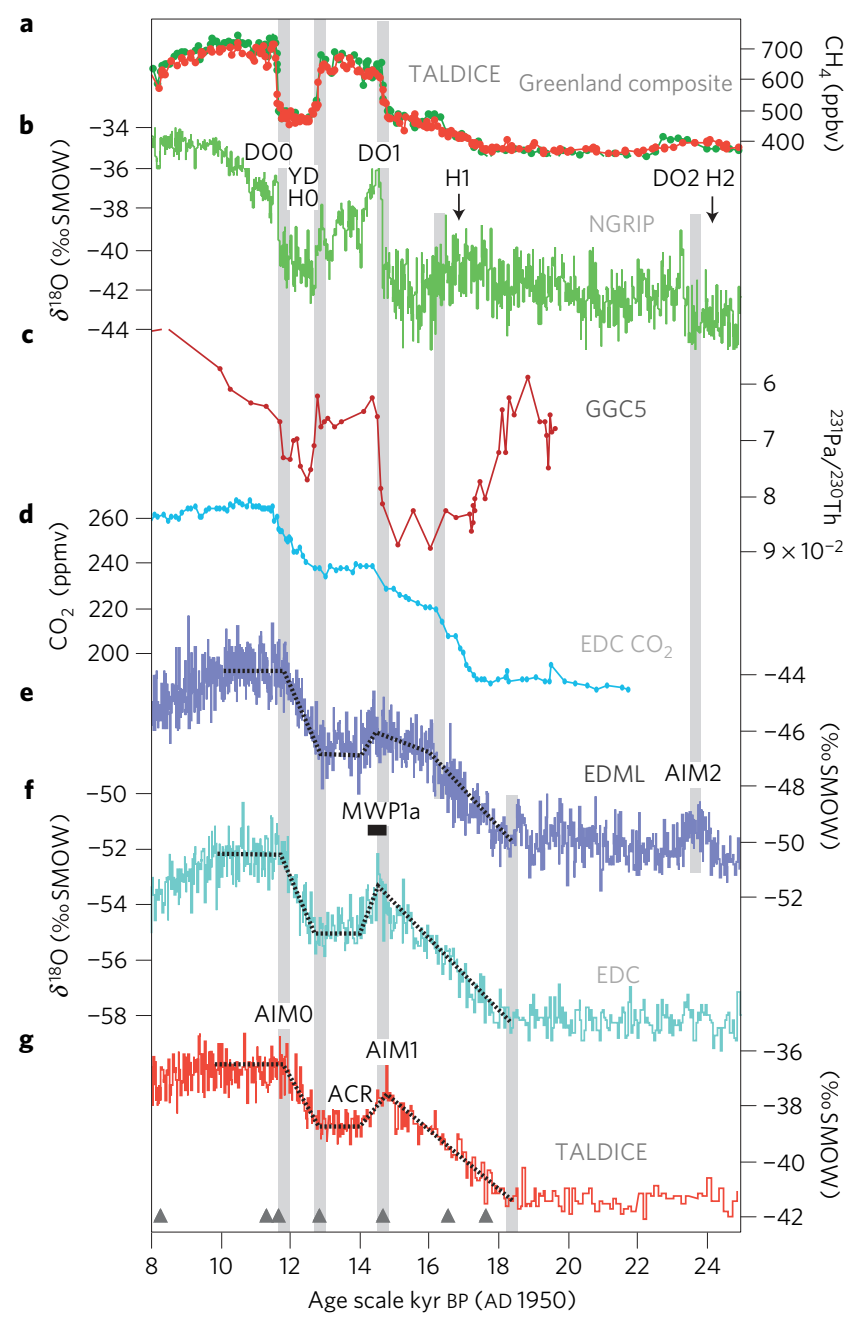

Figure 2 | Compilation of palaeoclimatic records from ice and marine cores to depict the bipolar sequence of events during the last termination. a, $\mathrm{CH}_{4}$ records of Greenland composite ${ }^{4}$ and TALDICE (this study); $\mathbf{b}, \delta^{18} \mathrm{O}$ record from NGRIP (ref. 6); c, ${ }^{231} \mathrm{~Pa} /{ }^{230}$ Th record of marine core GGC5, from Bermuda rise in the deep western subtropical Atlantic, taken as a proxy for Atlantic meridional overturning circulation strength ${ }^{19} ; \mathbf{d}, \mathrm{CO}_{2}$ from EDC (ref. 18); e, $\delta^{18} \mathrm{O}$ record from EDML (ref. 1); f, $\delta^{18} \mathrm{O}$ record from EDC (ref. 10); $\mathbf{g}, \delta^{18} \mathrm{O}$ record from TALDICE (this study). EDML, EDC and TALDICE are synchronized on the GICC05 timescale using a new inverse method. GGC5 data are shown on their own radiocarbon timescale. The dotted lines correspond to the ramps obtained with the Rampfit and Breakfit software. The YD and DO interstadials are indicated ${ }^{5,6}$. The black horizontal bar corresponds to MWP1a (ref. 22); the arrows represent the ages of Heinrich layers 1 and 2. The triangles indicate synchronization $\mathrm{CH}_{4}$ tie points. The grey vertical bars correspond to the AIM2 event, the start of the deglaciation (18.2 $\pm 0.7 \mathrm{kyr} B P)$, the slowing of the warming at EDML $(16.0 \pm 0.2 \mathrm{kyr} B P)$, the AIM1 event $(14.7 \pm 0.3 \mathrm{kyr} B P)$, the end of the ACR $(12.7 \pm 0.3)$ and the AIMO $(11.9 \pm 0.3)$ event as inferred from $\delta^{18} \mathrm{O}$ ice-core records (this study).

at EDC. The lack of an AIM2 signal in the Indo-Pacific sector is confirmed by the TALDICE data (Fig. 2). A specific deglacial pattern is observed in EDML-DF ice cores compared with EDCTALDICE. These two last cores show a $\sim 3.5 \mathrm{kyr}$ warming at an almost constant rate ( 1 and $1.3 \% 0 \delta^{18} \mathrm{O} \mathrm{kyr}^{-1}$, respectively) peaking in AIM1, whereas EDML-DF depict a reduced warming rate (about $0.5 \% 0 \delta^{18} \mathrm{O} \mathrm{kyr}^{-1}$ ) between $16.0 \pm 0.2 \mathrm{kyr}$ вр and AIM1 (Figs 2 and 3). This slowdown of the warming can be also depicted from EDC-TALDICE records but is negligible with respect to EDML-DF. 

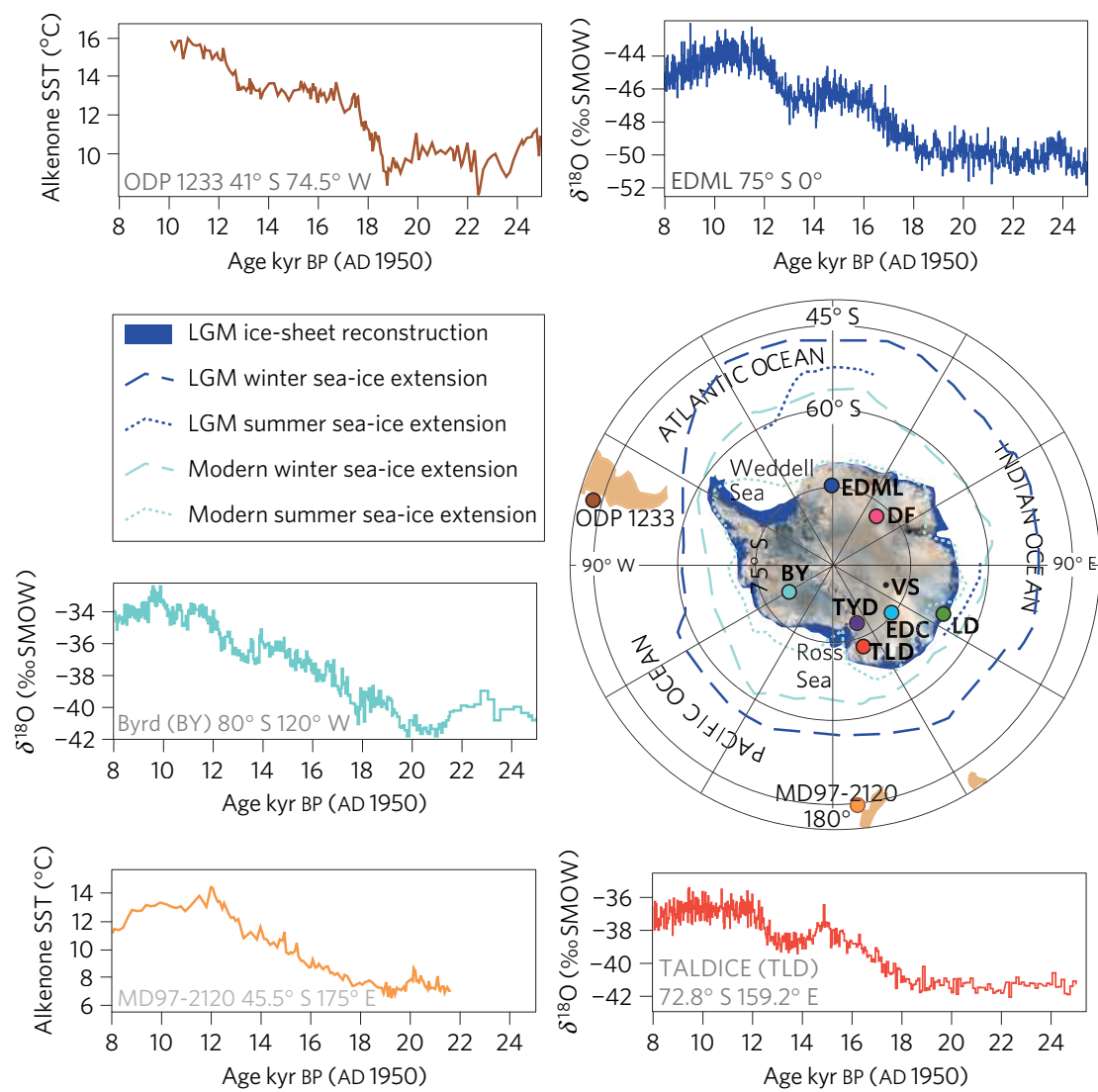
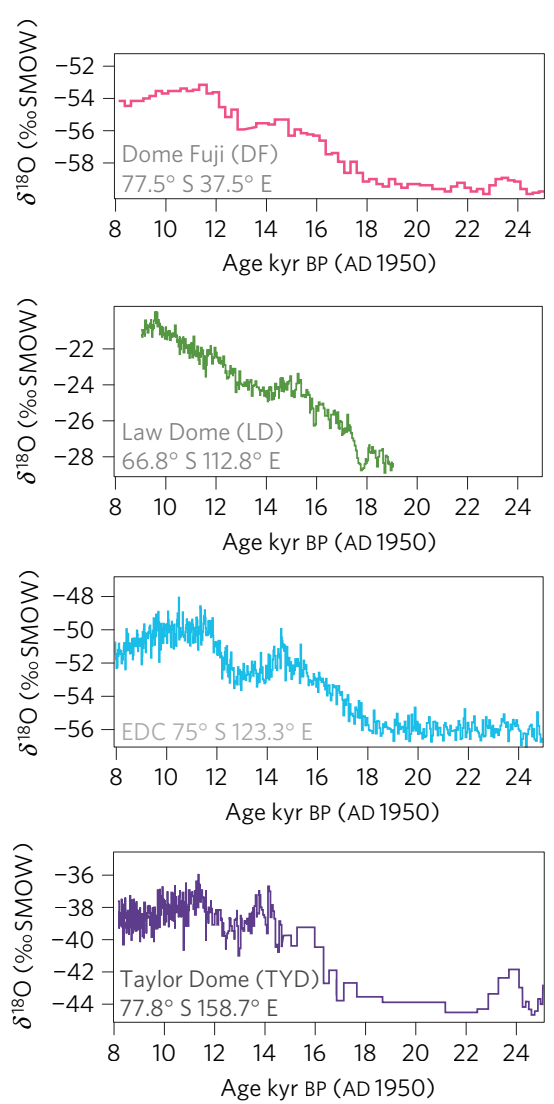

Figure 3 | Compilation of Southern Hemisphere palaeoclimatic records from ice and marine-sediment cores during the last deglaciation. From top left in clockwise order, alkenone-SST record from ODP 1233 (ref. 16); $\delta^{18} \mathrm{O}$ record from EDML (ref. 1), DF (ref. 9), LD (ref. 11), EDC (ref. 10), TYD (ref. 3) and TALDICE (this study); alkenone-SST record from MD97-2120 (ref. 17); $\delta^{18} \mathrm{O}$ record from Byrd ${ }^{28}$. EDML, EDC and TALDICE are synchronized on the GICC05 timescale using a new inverse method. DF, LD, TYD and Byrd data are shown on their own timescale. ODP 1233 data are shown on its timescale ${ }^{16}$ and MD97-2120 on the timescale developed by ref. 29. The map also shows, with circles, the locations of the ice cores of the Antarctic Ice Sheet and sediment cores in the Southern Ocean cited in the text (VS: Vostok). In blue, a sketch of the LGM ice-sheet reconstruction. The blue and light-blue lines show LGM and modern winter (dashed lines) and summer (dotted lines) sea-ice extension ${ }^{30}$, respectively.

Albeit hampered by the lack of coherent age scales, the comparison of the deglaciation $\delta^{18} \mathrm{O}$ records obtained on various ice cores (Fig. 3) reveals regional site-specific patterns in terms of warming rates and magnitudes. A change in the rate of warming around $16.7 \mathrm{kyr}$ в $\mathrm{P}$ is also observed in an alkenone-sea surface temperature (SST) record at the ODP 1233 site near the Chilean coast ${ }^{16}$, although no further slope changes corresponding to AIM1 or ACR are shown. Conversely, the alkenone-SST record from a marine core (MD97-2120) collected in the Southwest Pacific ${ }^{17}$ shows an uninterrupted deglacial warming comparable to EDC-TALDICE records (Fig. 3). Therefore, both marine and ice core sequences depict a different rate of warming in the South Chilean coast/South Atlantic compared with the Indo/South Pacific, starting around $16 \mathrm{kyr}$ вр. The warming slowdown at EDML-DF is synchronous with the deceleration of the $\mathrm{CO}_{2}$ rise ${ }^{18}$, with the unusually high ${ }^{231} \mathrm{~Pa} /{ }^{230} \mathrm{Th}$ ratio in abyssal North Atlantic sediments interpreted as a weaker Atlantic meridional overturning circulation strength ${ }^{19}$, with minimum $\delta^{18} \mathrm{O}$ values at NGRIP (Fig. 2) and with distinct change in the strength of the Asian monsoon ${ }^{20}$. Specific changes in the Atlantic sector linked with atmospheric circulation (westerly wind position), winter sea-ice extension and Antarctic Bottom Water formation may be involved in the parallel deceleration of the $\mathrm{CO}_{2}$ rise. Although it is not clearly imprinted in the Atlantic sector (EDML-DF), the culmination of AIM1 is clearly visible in the Indian Ocean sector dated at $14.7 \pm 0.3 \mathrm{kyr}$ в on the TALDICE-1 chronology, $14.5 \pm 0.2 \mathrm{kyr}$ вP on the new EDC age scale $^{8}$ (Fig. 2). Between $16.0 \mathrm{kyr}$ вP and AIM1, different trends of moisture-source temperatures are derived from deuterium-excess data $^{15}$ at EDML and EDC. Different shifts in moisture sources are probably linked to reorganization of atmospheric circulation at basin scale. A southward displacement of westerly winds has recently been reported ${ }^{21}$ during Northern Hemisphere stadials. The different rates of warming between $16.0 \mathrm{kyr}$ BP and AIM1, observed at EDML-DF and EDC-TALDICE, suggest a different expression of the bipolar see-saw in the two regions. The underlying mechanisms will be investigated in future through new observations and modelling studies.

The onset of ACR in TALDICE and EDC chronologies corresponds to the DO1 onset ( $14.7 \mathrm{kyr}$ BP) in the NGRIP ice core ${ }^{5}$ and with the minimum $\Delta$ age chronology at LD (ref. 11). The ACR onset also corresponds to the timing of the exceptionally large Melt Water Pulse 1a (MWP1a) inferred from relative sea-level records. MWP1a occurred at around $14.6 \mathrm{kyr}$ вP with a global sea-level rise between 10 and $20 \mathrm{~m}$ in a few centuries ${ }^{22}$. Observational data and modelling studies indicate that Antarctica contributed partly to MWP1a (ref. 13). Our new synchronized isotopic records suggest that the ACR could be a response to MWP1a, which in turn may partially originate from Antarctica after a prolonged deglacial warming. EDML and TALDICE are located close to the most important areas of Antarctic deepwater formation. A massive freshwater release in the high-latitude Southern Ocean is expected to shut down convection, reduce southward heat transport and increase sea ice and associated albedo feedbacks, inducing high-latitude Southern Ocean cooling ${ }^{23}$. This effect is still 
a subject of debate between modelling groups ${ }^{7,24}$, which reinforces the importance of palaeoclimate records as targets of numerical simulations. Our data support the hypothesis that the DO1 (B/A) is due to a sudden Atlantic meridional overturning circulation recovery from the Heinrich 1 event $^{7}$ and by a decrease in Antarctic Bottom Water formation in competitive see-saw behaviour with North Atlantic Deep Water ${ }^{25}$.

There is now growing evidence that the end of the YD in the North shows the same characteristics of a typical abrupt DO warming event (DO0), associated with the early Antarctic Holocene optimum (AIM0) in a thermal bipolar see-saw pattern ${ }^{26}$. The ACR-AIM0 transition starts synchronously at $12.7-12.9 \mathrm{kyr}$ в in TALDICE-EDC-EDML (see Supplementary Information), synchronously with the precisely dated glacier retreat in New Zealand ${ }^{27}$, demonstrating a coherent picture for the end of deglaciation between mid- and high latitudes of the Southern Hemisphere. The weaker $\delta^{18} \mathrm{O}$ amplitude of ACR and AIM0 at TALDICE, compared with other EAP ice cores (Fig. 2), can be explained with local elevation and air-mass-trajectory changes (see Supplementary Information).

Located in the Ross Sea sector, TLD is the most remote icecore site from the North Atlantic 'centre of action', and still clearly shows a thermal bipolar see-saw behaviour during the last deglaciation. This paper highlights the distinct regional climate fingerprint between the Indo-Pacific and the Atlantic sectors between $16.0 \mathrm{kyr}$ вP and AIM1. Understanding and simulating the bipolar and peri-Antarctic sequences and patterns of events and their interplay with the carbon cycle are critical challenges for earth and climate system modelling, although many gaps remain in the description of the past regional Antarctic climate variability.

\section{References}

1. EPICA Community Members. One-to-one coupling of glacial climate variability in Greenland and Antarctica. Nature 444, 195-198 (2006).

2. Stocker, T. F. \& Johnsen, S. J. A minimum thermodynamic model for the bipolar seesaw. Paleoceanography 18, 1087 (2003).

3. Steig, E. J. et al. Synchronous climate changes in Antarctica and the North Atlantic. Science 282, 92-95 (1998).

4. Blunier, T. et al. Synchronization of ice core records via atmospheric gases. Clim. Past 3, 325-330 (2007).

5. Steffensen, J. P. et al. High-resolution Greenland ice core data show abrupt climate change happens in few years. Science 321, 680-684 (2008).

6. North Greenland Ice Core Project Members. High resolution climate record of the northern hemisphere reaching into the last interglacial period. Nature 431, 147-151 (2004).

7. Liu, Z. et al. Transient simulation of last deglaciation with a new mechanism for Bølling-Allerød warming. Science 325, 310-314 (2009).

8. Lemieux-Dudon, B. et al. Consistent dating for Antarctic and Greenland ice cores. Quat. Sci. Rev. 29, 8-20 (2010).

9. Watanabe, O. et al. Homogeneous climate variability across East Antarctica over the past three glacial cycles. Nature 422, 509-512 (2003).

10. Jouzel, J. et al. Orbital and millennial Antarctic climate variability over the past 800,000 years. Science 317, 793-796 (2007).

11. Morgan, V. et al. Relative timing of deglacial climate events in Antarctica and Greenland. Science 297, 1862-1864 (2002).

12. Mulvaney, R. et al. The transition from the last glacial period in inland and near-coastal Antarctica. Geophys. Res. Lett. 27, 2673-2676 (2000).

13. Clark, P. U. et al. The Last Glacial Maximum. Science 325, 710-714 (2009).
14. Schaefer, J. M. et al. Near-synchronous interhemispheric termination of the Last Glacial Maximum in mid-latitudes. Science 312, 1510-1513 (2006).

15. Stenni, B. et al. The deuterium excess records of EPICA Dome C and Dronning Maud Land ice cores (East Antarctica). Quat. Sci. Rev. 29, 146-159 (2010).

16. Lamy, F. et al. Modulation of the bipolar seesaw in the Southeast Pacific during Termination 1. Earth Planet. Sci. Lett. 259, 400-413 (2007).

17. Pahnke, K. \& Sachs, J. P. Sea surface temperatures of southern midlatitudes 0-160 kyr B.P. Paleoceanography 21, PA2003 (2006).

18. Monnin, E. et al. Atmospheric $\mathrm{CO}_{2}$ concentrations over the last glacial termination. Science 291, 112-114 (2001).

19. McManus, J. F., Francois, R., Gherardi, J-M., Keigwin, L. \& Brown-Leger, S. Collapse and rapid resumption of Atlantic meridional circulation linked to deglacial climate changes. Nature 428, 834-837 (2004).

20. Broecker, W. S. et al. Putting the Youger Dryas cold event into context. Quat. Sci. Rev. 29, 1078-1081 (2010).

21. Denton, G. H. et al. The last glacial termination. Science 328, 1652-1656 (2010).

22. Deschamps, P. et al. Synchroneity of Meltwater Pulse 1A and the Bølling onset: New evidence from the IODP 'Tahiti Sea-Level' expedition. Geophys. Res. Abstr. 11, EGU2009-10233 (2009).

23. Weaver, A. J., Saenko, O. A., Clark, P. U. \& Mitrovica, J. X. Meltwater Pulse 1A from Antarctica as a trigger of the Bølling-Allerød warm interval. Science 299, 1709-1713 (2003).

24. Knorr, G. \& Lohmann, G. Southern Ocean origin for the resumption of Atlantic thermohaline circulation during deglaciation. Nature 424, 532-536 (2003).

25. Pahnke, K., Goldstein, S. L. \& Hemming, S. R. Abrupt changes in Antarctic intermediate water circulation over the past 25,000 years. Nature Geosci. 1, 870-874 (2008).

26. Masson-Delmotte, V. et al. Abrupt change of Antarctic moisture origin at the end of Termination II. Proc. Natl Acad. Sci. USA 107, 12091-12094 (2010).

27. Kaplan, M. R. et al. Glacier retreat in New Zealand during the Youger Dryas stadial. Nature 467, 194-197 (2010).

28. Blunier, T. \& Brook, E. J. Timing of millennial-scale climate change in Antarctica and Greenland during the last glacial period. Science 291, 109-112 (2001).

29. Rose, K. A. et al. Upper-ocean-to-atmosphere radiocarbon offsets imply fast deglacial carbon dioxide release. Nature 466, 1093-1097 (2010).

30. Gersonde, R., Crosta, X., Abelmann, A. \& Armand, L. Sea-surface temperature and sea ice distribution of the Southern Ocean at the EPILOG Last Glacial Maximum-a circum-Antarctic view based on siliceous microfossil records. Quat. Sci. Rev. 24, 869-896 (2005).

\section{Acknowledgements}

We thank the logistic and drilling TALDICE team. We thank M. Mudelsee for discussion regarding the use of the Rampfit software (www.mudelsee.com). The Talos Dome Ice Core Project (TALDICE), a joint European programme led by Italy, is funded by national contributions from Italy, France, Germany, Switzerland and the United Kingdom. The main logistical support was provided by Programma Nazionale di Ricerche in Antartide (PNRA) at Talos Dome. This is TALDICE publication no 9. A file containing the new ice core $\delta^{18} \mathrm{O}$ record from TALDICE can be downloaded from the website of the World Data Center for Paleoclimatology (www.ncdc.noaa.gov/paleo) and from the TALDICE website (www.taldice.org).

\section{Author contributions}

B.S., D.B., M. Baumgartner, M. Bonazza, S.F., L.G., V.M-D., B.M., A.S., S.S. and E.S. contributed to new TALDICE $\delta^{18} \mathrm{O}$ and $\mathrm{CH}_{4}$ measurements. D.B., S.A., E.B., M. Baroni, E. Capron, E. Castellano, B.D., A.L., B.L-D., C.M., M.M., B.N., F.P., J.R.P., C.R., M.S. and R.U. contributed to measurements and modelling used for TALDICE dating and ice flow description. B.S. and M.F. prepared the figures and wrote most of the manuscript with the main contributions of D.B., J.C., B.D., V.M-D., J.J., B.L-D., B.N., J.R.P. and T.F.S. All authors worked on the comparison of the different records and their interpretations.

\section{Additional information}

The authors declare no competing financial interests. Supplementary information accompanies this paper on www.nature.com/naturegeoscience. Reprints and permissions information is available online at http://npg.nature.com/reprintsandpermissions. Correspondence and requests for materials should be addressed to M.F. 